\title{
AVALIAÇÃO DA TÉCNICA DE ADAPTAÇÃO DE LODO ANAERÓBIO AO BIODIESEL EM MEIO LÍQUIDO
}

\author{
B. F. OLIVEIRA ${ }^{1}$, M. S. KASHIWABARA ${ }^{1}$, E. J. RIBEIRO ${ }^{1}$ e P. A. VIEIRA ${ }^{1}$ \\ ${ }^{1}$ Universidade Federal de Uberlândia, Faculdade de Engenharia Química \\ E-mail para contato: bian.oliveira@bol.com.br; patriciavieira@ufu.br
}

\begin{abstract}
RESUMO - Os avanços tecnológicos adquiridos pelo ser humano fizeram com que aguçasse a busca por fontes de energia que não agredissem o meio ambiente. O uso desenfreado de biodiesel pode causar contaminações de solo e de água, e processos biológicos, envolvendo uma grande gama de microrganismos como fungos, bactérias e culturas mistas, têm se tornado uma alternativa no tratamento de efluentes contaminados por biodiesel. Assim, o objetivo deste trabalho foi avaliar uma técnica na adaptação de lodo, advindo da unidade de tratamento anaeróbio de efluente da indústria de produção de cigarros, ao biodiesel presente em meio líquido. Decantou-se $500 \mathrm{~mL}$ de lodo, do qual se retirou $10 \mathrm{~mL}$ de inóculo e adicionou-se em erlenmeyers com capacidade de $500 \mathrm{~mL}$, contendo 200 $\mathrm{mL}$ de meio de cultura previamente esterilizado. A esta suspensão foi adicionado biodiesel como fonte de carbono e energia. Foram purgados por 5 min com gás nitrogênio, visando eliminar o oxigênio presente, garantindo a condição anaeróbia, e tampados com rolha de cortiça. Os erlenmeyers foram postos sob agitação em mesa oscilatória. O meio de cultura foi substituído a cada 2 dias de processo e a concentração de biodiesel foi aumentada a cada 15 dias. As variáveis acompanhadas foram $\mathrm{pH}$ e DQO, e o crescimento microbiano foi observado visualmente. Os resultados mostraram que a técnica de adaptação adotada foi eficiente por ter proporcionado ao lodo a capacidade de remoção de DQO acima de $80 \%$ em 7 dias de processo.
\end{abstract}

\section{INTRODUÇÃO}

Desde a I Revolução Industrial, há um agravamento dos problemas ambientais ligados ao mal-uso do homem em relação aos seus recursos naturais. Advindo a isto, também cresceu a preocupação em tentar reverter tais malefícios. A produção de biocombustíveis, em especial o biodiesel, foi uma das alternativas para solucionar os problemas e alcançar um balanço energético mais favorável (Oliveira, 2016).

O biodiesel é fabricado a partir de fontes renováveis, tais como óleo de soja, gordura animal ou vegetal, óleo de algodão, por um processo de transesterificação. Sua classificação como energia sustentável se dá pelo fato de que sua combustão libera uma menor quantidade de dióxido de carbono em relação aos combustíveis fósseis, e por ser uma energia renovável (Corrêa; Arbilla, 2006).

Entretanto, a grande utilização do biodiesel aumenta os riscos de contaminação do ambiente, principalmente do solo e da água, prejudicando este balanço energético do 
biocombustível. Isso ocorre por conta de possíveis derramamentos acidentais durante todo o processo de produção, transporte e armazenamento dele. Por conta disso, estudos são feitos para biorremediação de ambientes contaminados por hidrocarbonetos de petróleo. Este método é baseado na atividade biológica de microrganismos, e por isso é preciso garantir condições ambientais favoráveis à sobrevivência, crescimento e atividade destes, a fim de se obter maiores índices de remoção de contaminantes (Braga et al., 2013).

Com base no exposto, o objetivo deste trabalho foi adaptar o lodo advindo de processo de tratamento anaeróbio de efluente do processamento de cigarros ao biodiesel presente em meio líquido.

\section{MATERIAIS E MÉTODOS}

\subsection{Biodiesel}

O biodiesel utilizado para o desenvolvimento desta pesquisa foi gentilmente fornecido pela Caramuru Alimentos S/A - São Simão - GO.

\subsection{Microrganismo}

O lodo denominado de C2 foi gentilmente cedido pela Souza Cruz - Fábrica Uberlândia- MG da unidade de tratamento anaeróbio de efluentes.

\subsection{Experimento De Adaptação}

A adaptação da cultura estudada foi feita em meio líquido (com água destilada), denominado de M1, cuja composição é apresentada na Tabela 1.

Tabela 1 - Composição do Meio M1

\begin{tabular}{|c|c|}
\hline Reagentes & Concentração $(\mathrm{g} / \mathrm{L})$ \\
\hline $\mathrm{NH}_{4} \mathrm{Cl}$ & 0,164 \\
\hline $\mathrm{K}_{2} \mathrm{HPO}_{4}$ & 0,005 \\
\hline $\mathrm{KH}_{2} \mathrm{PO}_{4}$ & 0,003 \\
\hline $\mathrm{MgSO}_{4} \cdot 7 \mathrm{H}_{2} \mathrm{O}$ & 0,200 \\
\hline $\mathrm{CaCl}_{2} \cdot 2 \mathrm{H}_{2} \mathrm{O}$ & 0,100 \\
\hline Extrato de Levedura & 0,500 \\
\hline $\mathrm{FeCl}_{3} \cdot 6 \mathrm{H}_{2} \mathrm{O}$ & 0,002 \\
\hline $\mathrm{MnCl}_{2} \cdot 4 \mathrm{H}_{2} \mathrm{O}$ & 0,0005 \\
\hline $\mathrm{NaHCO}_{3}$ & 0,0042 \\
\hline
\end{tabular}

Vale ressaltar, que o bicarbonato de sódio foi utilizado como tamponante do meio.

Para adaptação do lodo ao biodiesel em meio líquido, foi decantado $500 \mathrm{~mL}$ de lodo em um béquer com capacidade de $1 \mathrm{~L}$, do qual foi retirado $10 \mathrm{~mL}$ de inóculo e adicionado em erlenmeyers com capacidade de $500 \mathrm{~mL}$, contendo $200 \mathrm{~mL}$ de meio de cultura M1 previamente esterilizados a $121^{\circ} \mathrm{C}$ e 1 atm. A esta suspensão foi adicionado biodiesel como fonte de carbono e energia. Os erlenmeyers foram purgados por 5 min com gás nitrogênio, 
visando eliminar o oxigênio presente e garantir a condição anaeróbia, e imediatamente foram tampados com rolha de cortiça, as quais foram adaptadas por uma mangueira. As pontas dessas mangueiras foram colocadas na superfície da água presente em frascos de penicilina de $100 \mathrm{~mL}$ para canalização e verificação dos gases formados. Os erlenmeyers foram postos sob agitação em mesa oscilatória termostatizada New Brunswick a $150 \mathrm{rpm}$ e temperatura ambiente. O meio de cultura foi substituído a cada 2 dias de processo devido a possibilidade de produção de substâncias tóxicas pelos microrganismos.

O critério de seleção adotado para aumentar a concentração de contaminantes no meio foi de 15 dias nas concentrações de biodiesel de 2,5 e 5,0 g/L. As variáveis acompanhadas foram $\mathrm{pH}$ e DQO e o crescimento microbiano foi observado, visualmente, através do aumento gradativo da turbidez do meio.

\subsection{Análises Quantitativas}

Análise de $\mathrm{pH}$ : A determinação do $\mathrm{pH}$ foi de acordo com o procedimento descrito em APHA (1998). A leitura do $\mathrm{pH}$ das amostras foi realizada pelo método potenciométrico, utilizando phmetro, introduzindo o eletrodo diretamente nas amostras líquidas.

Análise de demanda química de oxigênio (DQO): Para a determinação da DQO por espectrofotometria foram realizados os seguintes passos empregando a preparação de solução de digestão para alta concentração (absorbância de $600 \mathrm{~nm}$ ): Adicionou-se em $500 \mathrm{~mL}$ de água destilada $10,126 \mathrm{~g} \mathrm{~K}_{2} \mathrm{Cr}_{2} \mathrm{O}_{7}$, grau padrão primário, previamente seco em $150^{\circ} \mathrm{C}$ por $2 \mathrm{~h}$, $167 \mathrm{~mL}$ de $\mathrm{H}_{2} \mathrm{SO}_{4}$ concentrado e $33,3 \mathrm{~g} \mathrm{HgSO}_{4}$. Dissolveu-se a temperatura ambiente e diluiu-se a $1000 \mathrm{~mL}$. Usaram-se as seguintes relações de reagentes e amostra: $2,5 \mathrm{~mL}$ de amostra; 1,5 mL da solução de dicromato e 3,5 mL da solução de ácido sulfúrico para os tubos de ensaio adequados para o bloco digestor. A digestão ocorreu por $2 \mathrm{~h}$ a $150^{\circ} \mathrm{C}$. Para o preparo da curva de calibração empregou-se 5 padrões de biftalato de potássio com DQO equivalentes para cobrir cada limite de concentração. Para o branco, usou-se os mesmos volumes de reagentes, tubos e procedimento de digestão das amostras.

\section{RESULTADOS E DISCUSSÕES}

As Figuras 1 e 2 mostram os resultados de remoção de DQO e valores de pH da adaptação do lodo às concentrações de 2,5 e 5,0 g/L de biodiesel em meio líquido.

Pode-se verificar por meio da Figura 1 que a remoção de DQO na menor concentração de biodiesel $(2,5 \mathrm{~g} / \mathrm{L})$ foi mais eficiente chegando a se atingir acima de $80 \%$ de remoção. Ao aumentar a concentração de biodiesel $(5,0 \mathrm{~g} / \mathrm{L})$ o lodo proporcionou uma remoção máxima de DQO em 7 dias de processo de $80 \%$. Após este período foi verificado uma queda na remoção, isto sugere que após os 7 dias de processo possivelmente houve a geração de maior quantidade de metabólitos que promoveu o aumento da DQO do meio e consequentemente a diminuição da remoção. Portanto, a máxima remoção obtida para a concentração tanto de 2,5 $\mathrm{g} / \mathrm{L}$ quanto para 5,0 g/L acontece em 7 dias de processo. Além disso, verifica-se que com o aumento da concentração de biodiesel no meio ocorre uma diminuição na eficiência de remoção de DQO, passando de valores acima de $85 \%$ para $2,5 \mathrm{~g} / \mathrm{L}$ e próximo a $80 \%$ para 5,0 $\mathrm{g} / \mathrm{L}$ de biodiesel no meio. 
Figura 1 - Remoção de DQO para 2,5 e 5,0 g/L de biodiesel.

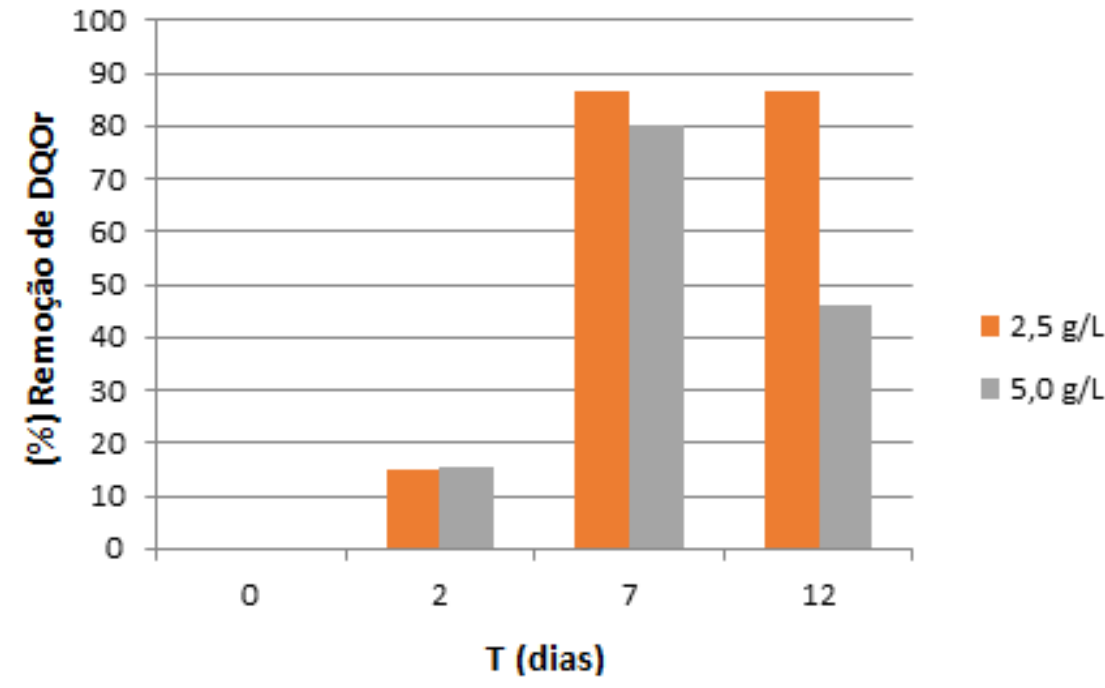

Figura $2-\mathrm{pH}$ para 2,5 e $5,0 \mathrm{~g} / \mathrm{L}$ de biodiesel.

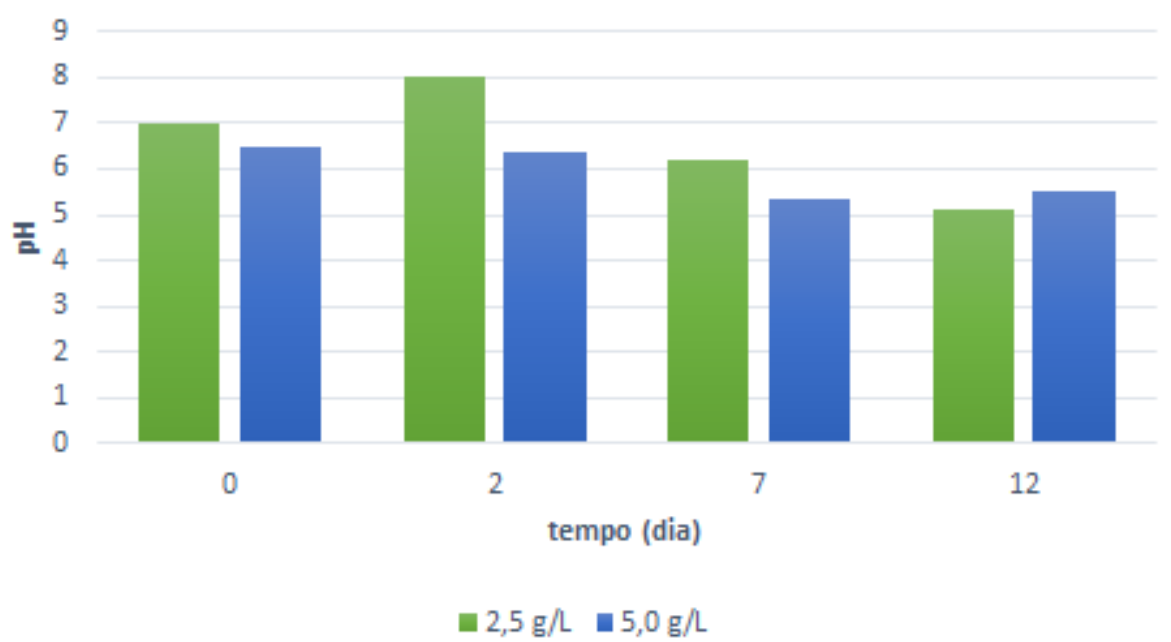

Ao analisar a Figura 2, observa-se que o pH do meio sofreu alterações ao longo do processo para ambas concentrações de biodiesel avaliadas.

\section{CONCLUSÕES}

A técnica de adaptação adotada neste trabalho foi eficiente por ter proporcionado ao lodo avaliado a capacidade de remoção de DQO acima de $80 \%$ em 7 dias de processo. 
Estudos posteriores serão desenvolvidos na avaliação de parâmetros que possam promover a melhoria da remoção de DQO.

\section{REFERÊNCIAS}

APHA. Standard Methods for the Examination of Water and Wastewater. 20th ed. APHA: Washington, 1998.

BRAGA, T. G.; PÓVOA, P. V.; PIRETE, L. M.; LEMOS, D. A.; CARDOSO, V. L.; RESENDE, M. M.; VIEIRA, P. A. Biorremediação de solo contaminado com biodiesel de processo (biodiesel e glicerina): avaliação de condições operacionais empregando reatores rotativo e de bandeja. X Congresso Brasileiro de Engenharia Química Iniciação Científica - Universidade Federal Rural do Rio de Janeiro, Vassouras - RJ, 2013.

CORRÊA, S. M.; ARBILLA, G. Emissão de poluentes não legislados por biodiesel. Rio de Janeiro, 2006.

OLIVEIRA, M. C. J. Diesel e biodiesel de murumuru e de soja: desempenho operacional de trator agrícola no preparo do solo. Doutorado em Agronomia - Universidade Estadual Paulista, Jaboticabal - SP, 2016.

\section{AGRADECIMENTOS}

Os autores agradecem ao apoio financeiro da Fundação de Amparo à Pesquisa do Estado de Minas Gerais - FAPEMIG, CAPES e CNPq - Brasil e à Faculdade de Engenharia Química (FEQUI-UFU) e as Empresas Caramuru Alimentos S/A - São Simão - GO, pelas amostras de biodiesel e a Souza Cruz- Fábrica Uberlândia, pela amostra de lodo anaeróbio. 